\title{
Intrachain energy transfer in silylene-spaced alternating donor-acceptor divinylarene copolymers $\uparrow$
}

\author{
Yen-Ju Cheng, Tsyr-Yuan Hwu, Jui-Hung Hsu and Tien-Yau Luh* \\ Department of Chemistry, National Taiwan University, Taipei, Taiwan 106 \\ Institute of Chemistry, Academia Sinica, Taipei, Taiwan 115. E-mail: tyluh@chem.sinica.edu.tw; \\ Fax: +886-2-2651-1488; Tel: +886-2-2789-8500
}

Received (in Cambridge, UK) 3rd July 2002, Accepted 23rd July 2002

First published as an Advance Article on the web 7th August 2002

Silylene-spaced donor-acceptor divinylarene copolymers are synthesized by hydrosilylation of bisalkynes 7 with bisvinylsilanes 3; efficient intrachain energy transfer between donor-acceptor chromophores is observed.

Conjugated copolymers with alternating donor/acceptor repeating units have received much attention because the intramolecular charge transfer within the chain may result in concomitant changes in band gaps, electrochemical and optical properties. ${ }^{1}$ Alternatively, intramolecular energy transfer along a non-conjugated supramolecular system or a polymer chain has been extensively investigated because it may serve as a useful model to mimic the natural light harvesting process. ${ }^{2} \mathrm{We}$ and others found that the silicon moiety in silylene spaced divinylarene copolymers $\mathbf{1}$ may serve as an insulating tetrahedral spacer so that there is no conjugation along the polymeric backbone. ${ }^{3,4}$ Intrachain chromophore interaction due to folding of the polymer has been observed in silylene-divinylbenzene copolymers 1a. ${ }^{3}$ It is known that photoinduced through-space charge transfer may occur in 4-donor-4'-acceptor substituted diphenyldimethylsilanes $2 .{ }^{5}$ Since $\mathbf{1}$ is synthesized by the<smiles>C/C=C/CN/C=C/S(C)(C)/C=C/[13CH]/C=C/[Si](C)(C)I</smiles>
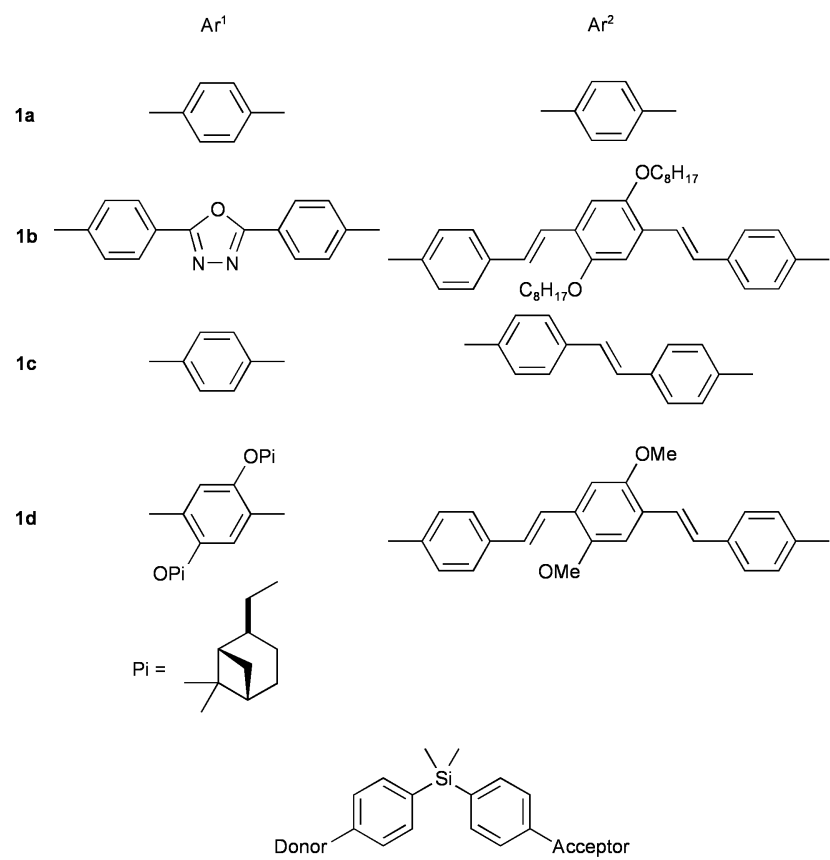

2

hydrosilylation of bisalkynes $\mathbf{7}$ with bisvinylsilanes $\mathbf{3},{ }^{3}$ the two neighboring chromophores in $\mathbf{1}$ can be different and alternating. It is envisaged that interaction between the neighboring

$†$ Electronic supplementary information (ESI) available: experimental details. See http://www.rsc.org/suppdata/cc/b2/b206308e/

chromphores may also take place leading to transfer of energy. We now describe the first example on the synthesis and photophysics of silylene-spaced alternating donor-acceptor copolymers 1 .

Our strategy was to synthesize a series of monomeric silylsubstituted divinylarenes 3. Based on the absorption and emission properties of these monomers (Table 1), a series of polymers 1 was designed so that the absorption of one chromophore $\left(\mathrm{Ar}^{2}\right)$ can overlap with the emission of the other chromophore $\left(\mathrm{Ar}^{1}\right)$. The synthesis of vinylsilanes $\mathbf{3}$ was based on the nickel-catalyzed silylolefination of the corresponding dithioacetals 5 followed by the reduction of the corresponding $\mathrm{Si}-\mathrm{O}$ bond in $\mathbf{6},{ }^{3}$ whereas a Sonogashira reaction was employed for the synthesis of bisalkynes $\mathbf{7}$. Hydrosilylation of $\mathbf{7}$ with $\mathbf{3}$ afforded the corresponding copolymers $\mathbf{1}$. Monomers 4 were obtained similarly from $\mathbf{7}$ and $\mathbf{8}$.

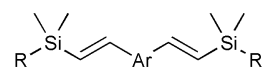

$\mathbf{R}$
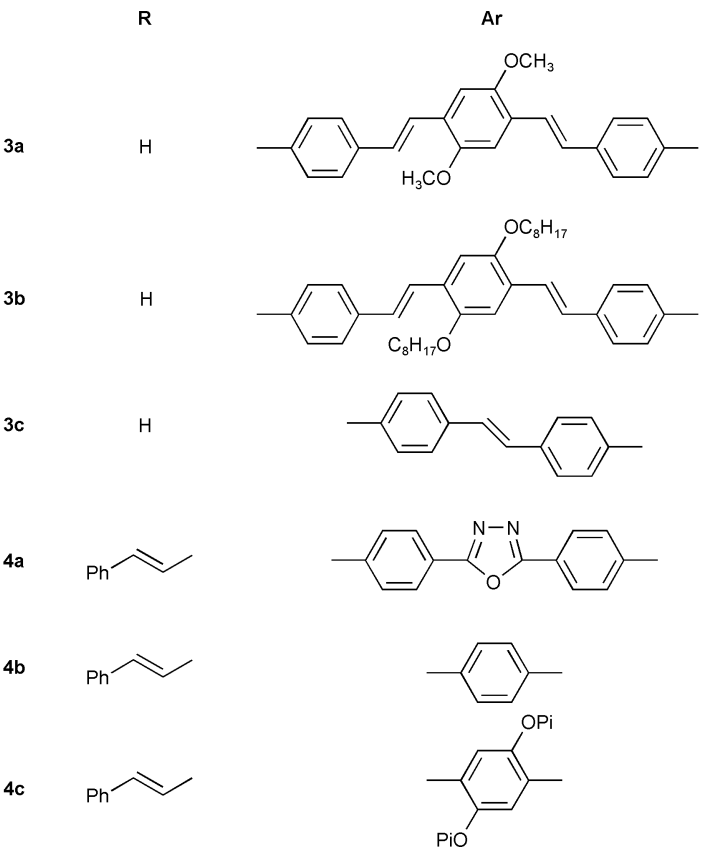

As shown in Table 1, the emission maximum of $\mathbf{4 a}$ matched well with the absorption maximum of $\mathbf{3 b}$. Fig. 1 shows the concentration dependent emission spectra (excitation at 324 $\mathrm{nm}$ ) of an equal molar mixture of $\mathbf{3 b}$ and $\mathbf{4 a}$. It is noteworthy that the intermolecular energy transfer between $\mathbf{4 a}$ and $\mathbf{3 b}$ does not proceed efficiently. The fluorescence spectrum (excitation at $324 \mathrm{~nm}$ ) for polymer $\mathbf{1 b}$ is also included in Fig. 1 for comparison, only emission from chromophore $\mathrm{Ar}^{2}$ being observed. This result indicated that complete energy transfer from diphenyloxadiazole moiety to terphenylene-tetravinylene chromophore occurred in $\mathbf{1 b}$. In a similar manner, efficient energy transfer from divinylbenzene to divinylstilbene in $\mathbf{~} \mathbf{c}$ and from divinyldialkoxybenzene to terphenylene-tetravinylene 


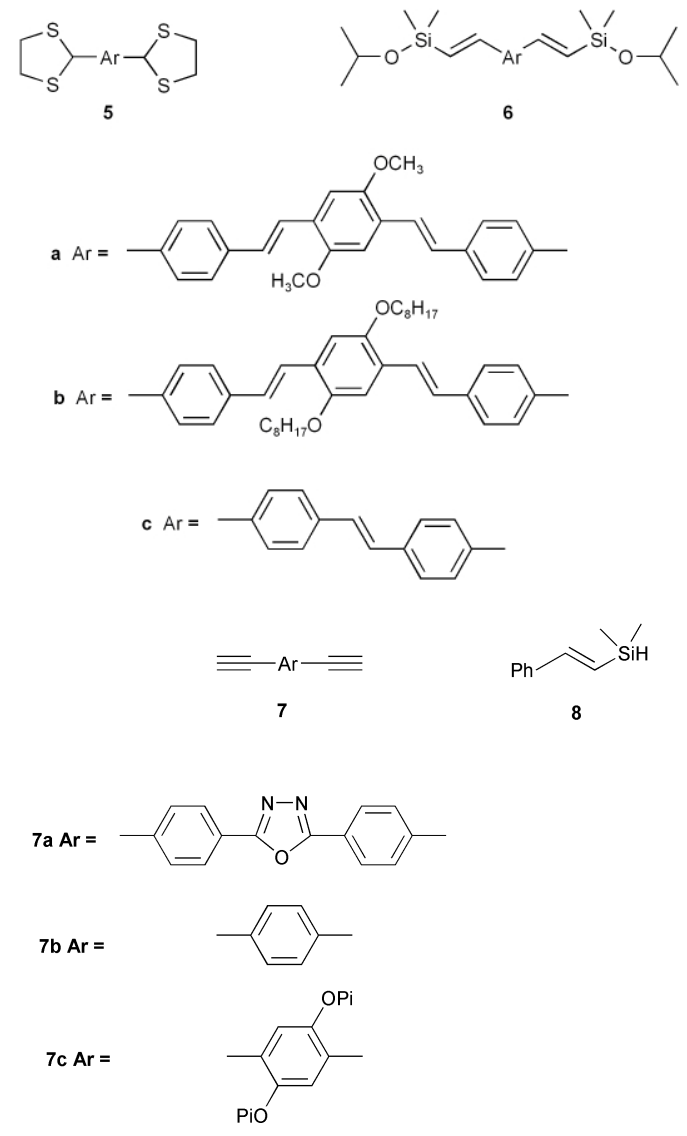

Table 1 Absorption and emission properties of polymers $\mathbf{1}$ and monomers 3 and 4

\begin{tabular}{llll}
\hline Substrate & $\lambda_{\max } / \mathrm{nm}$ & $\lambda_{\mathrm{em}} / \mathrm{nm}$ & $M_{\mathrm{n}}(\mathrm{PDI})$ \\
\hline 1b & 328,411 & 471,495 & $4100(1.5)$ \\
1c & 345,355 & 396,415 & $3200(2.7)$ \\
1d & 345,408 & 468,496 & $3990(1.5)$ \\
3a & 338,411 & 467,490 & \\
3b & 348,413 & 467,490 & \\
3c & 355 & 392,411 & \\
4a & 324 & $363,384,401$ & \\
4b & 263,300 & 334,347 & \\
4c & 262,360 & 418 & \\
\hline
\end{tabular}

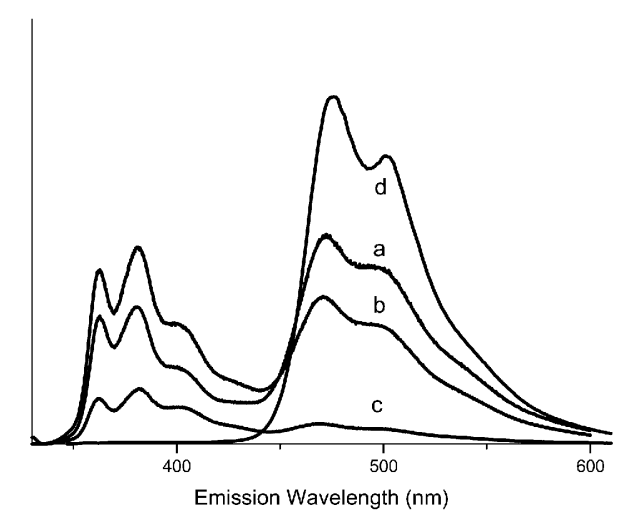

Fig. 1 Concentration dependent fluorescence spectra (excitation wavelength: $324 \mathrm{~nm}$ ) of an equal molar mixture of $\mathbf{3 b}$ and $\mathbf{4 a}$ in $\mathrm{CHCl}_{3}$ (a: $1 \times$ $10^{-1} \mathrm{~g} \mathrm{~mL}^{-1}$; b: $1 \times 10^{-2} \mathrm{~g} \mathrm{~mL}^{-1}$; c: $\left.1 \times 10^{-3} \mathrm{~g} \mathrm{~mL}^{-1}\right)$ and (d) fluorescence spectrum (excitation wavelength: $324 \mathrm{~nm}$ ) of $\mathbf{1 b}$ in $\mathrm{CHCl}_{3}$.

chromophore in 1d was observed (Figs. 2 and 3). The emission profiles remained essentially unchanged with concentration (up

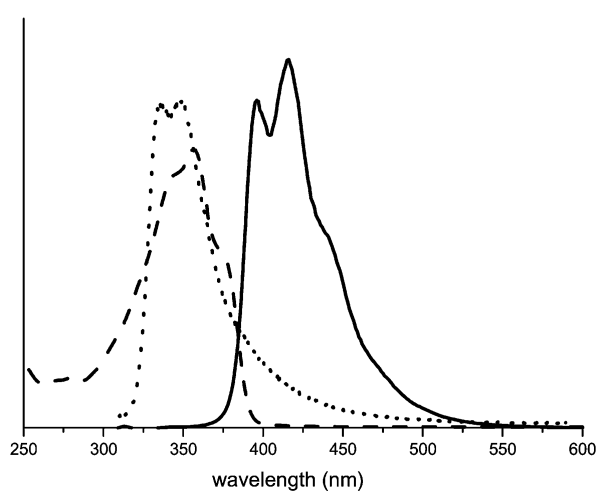

Fig. 2 Emission spectra (excitation wavelength: $300 \mathrm{~nm}$ ) of $\mathbf{1 c}(-), \mathbf{4 b}(\cdots)$ and absorption spectrum of $\mathbf{3 c}(---)$ in $\mathrm{CHCl}_{3}$.

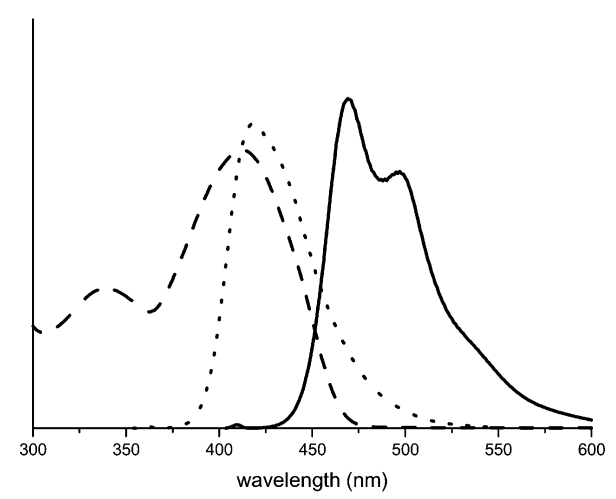

Fig. 3 Emission spectra (excitation wavelength: $360 \mathrm{~nm}$ ) of $\mathbf{1 d}(-), \mathbf{4 c}(\cdots)$ and absorption spectrum of $\mathbf{3 a}(---)$ in $\mathrm{CHCl}_{3}$.

to 100 fold) and with solvents ( $<3 \mathrm{~nm}$ in benzene, $\mathrm{CHCl}_{3}$, THF and EtOAc). Energy transfer therefore should occur within the polymer chain. Photoinduced charge transfer, ${ }^{5}$ if any, would apparently play little role in these polymers.

We thank the Ministry of Education and the National Science Council for financial support.

\section{Notes and references}

$\ddagger$ All new compounds gave satisfactory spectroscopic and analytical data. The details are described in the ESI. $\dagger$

1 T. Yamamoto, Z.-h. Zhou, T. Kanbara, M. Shimura, K. Kizu, T. Maruyama, Y. Nakamura, T. Fukuda, B.-L. Lee, N. Ooba, S. Tomaru, T. Kurihara, T. Kaino, K. Kubota and S. Sasaki, J. Am. Chem. Soc., 1996, 118, 10389.

2 S. E. Webber, Chem. Rev, 1990, 90, 1469; A. Adronov S. L. Gilat, J. M. J. Fréchet, K. Ohta, F. V. R. Neuwahl and G. R. Fleming, J. Am. Chem. Soc., 2000, 122, 1175; M. A. Fox, Acc. Chem. Res, 1999, 32, 201; C. Devadoss, P. Bharathi and J. S. Moore, J. Am. Chem. Soc., 1996, 118, 9635 .

3 R.-M. Chen, K.-M. Chien, K.-T. Wong, B.-Y. Jin and T.-Y. Luh, J. Am. Chem. Soc., 1997, 119, 11321.

4 R. J. P. Corriu, C. Guerin, B. Henner, T. Kuhlmann, A. Jean, F. Garnier and A. Yassar, Chem. Mater, 1990, 2, 351; Y. Pang, S. Ijadi-Maghsoodi and T. J. Barton, Macromolecules, 1993, 26, 5671; H. K. Kim, M.-K. Ryu and S.-M. Lee, Macromolecules, 1997, 30, 1236; Y.-J. Miao and G. C. Bazan, Macromolecules, 1997, 30, 7414; A. Mori, E. Takahisa, H. Kajiro, Y. Nishihara and T. Hiyama, Macromolecules, 2000, 33, 1115; A Kunai, E. Toyoda, I. Nagamoto, T. Horio and M. Ishikawa, Organometallics, 1996, 15, 75; H. Li and R. West, Macromolecules, 1998, 31, 2866 .

5 C. A. van Walree, M. R. P. Roest, W. Schuddeboom, L. W. Jenneskens, J. W. Verhoeven, J. M. Warman, H. Kooijman and A. L. Spek, J. Am. Chem. Soc, 1996, 118, 8395; A. Zehnacker, F. Lahmani, C. A. Van Walree and L. W. Jenneskens, J. Phys. Chem. A, 2000, 104, 1377. 